\title{
Medical Student And Faculty Perceptions Of Undergraduate Surgical Training In The South African And Swedish Tertiary Institutions: A Cross-Sectional Survey
}

This article was published in the following Dove Press journal:

Advances in Medical Education and Practice

\section{Alex J Scott (1D) \\ Gustaf Drevin (D) ${ }^{2}$ \\ Lordan Pavlović ${ }^{2}$ \\ Magnus Nilsson ${ }^{3}$ \\ Jake EJ Krige 4 \\ Eduard Jonas ${ }^{4}$}

'Faculty of Health Sciences, University of Cape Town, Cape Town, South Africa; ${ }^{2}$ Department of Medicine, Karolinska Institutet, Stockholm, Sweden; ${ }^{3}$ Division of Surgery, Karolinska Institutet,

Stockholm, Sweden; ${ }^{4}$ Department of Surgery, University of Cape Town, Cape Town, South Africa
Correspondence: Alex J Scott

Faculty of Health Sciences, University of Cape Town, Observatory, Barnard Fuller Building, Cape Town 7935, South Africa Tel +27 21 4066346

Email sctale00I@uct.ac.za
Purpose: To evaluate and compare medical student and faculty perceptions of undergraduate surgical training and compare results between South Africa and Sweden.

Patients and methods: An electronic, online questionnaire was anonymously distributed to medical students and surgical faculty at the University of Cape Town (UCT), South Africa, and the Karolinska Institutet (KI), Sweden. The questionnaire explored the perceptions of medical students and surgical faculty regarding the current undergraduate surgical curriculum, as well as existing clinical and theoretical instructional methods.

Results: A total of 120 students (response rate of $24.4 \%$ ) and 41 faculty (response rate of $74.5 \%$ ) responded. Students believed they ought to receive significantly more teaching when compared to surgical faculty $(p=0.018)$. Students and faculty generally agreed that students should expect to study approximately six to $20 \mathrm{hrs}$ per week outside of clinical duty. There was general agreement that "small-group tutorials" was the area students learn the most from, whereas students reported "lectures" least helpful. Registrars were reported as the first person students should consult regarding patient care. Fifty-one (42.5\%) medical students believed that faculty viewed students as an inconvenience, and $42(35.0 \%)$ students believed that faculty would rather not have students on the clinical team. The majority of faculty $(68.3 \%)$ reported significantly more negative views on the current undergraduate surgical curriculum when compared to students $(p=0.002)$. UCT faculty reported giving significantly less feedback to students during their surgical rotation when compared to KI faculty ( $p=0.043)$.

Conclusion: Significant differences exist between surgical faculty and medical student perceptions regarding undergraduate surgical training in developing and developed countries. In order to increase surgical interest among undergraduate medical students, it is imperative for surgical educators to be aware of these differences and find specific strategies to bridge this gap.

Keywords: surgical education, curriculum, perception, survey

\section{Introduction}

The surgical rotation in an undergraduate medical degree is often the first introduction to surgery for medical students. It is during this period that their experience may positively or negatively affect their decision to pursue a career in surgery. ${ }^{1}$ By creating a positive learning environment, which has been reported to be a critical aspect of successful education, medical students may obtain greater satisfaction during their surgical rotation. ${ }^{2}$ This has been shown to be facilitated by improved quality of student-instructor 
communication, active participation by the student in the learning process, realistic academic expectations, and an atmosphere of learning that is safe and respectful. ${ }^{3}$

In general, undergraduate medical education brings about transition in many ways, such as the often anxious arrival at medical school, frequent changes in clinical settings, and the adoption of increased clinical responsibility for patient care. Although the basic objective of the undergraduate medical and surgical curriculum still is to prepare students to enter the practice of medicine, the manner in which they are taught is rapidly evolving, especially in the discipline of surgery. ${ }^{4}$ It has even been suggested that the historic apprenticeship-like training no longer exists in the modern era of surgical education. ${ }^{5}$ The current surgical curriculum focuses on several educational methods and environments, which include lectures, smallgroup tutorials, the operating theater, and teaching wardrounds. ${ }^{6}$ With the ever changing demographic profile of medical students and surgical trainees, there needs to be a focus on implementing more effective and efficient educational curricula. ${ }^{7}$

Though a number of studies have addressed the views and perceptions of medical students regarding undergraduate surgical training, there is a paucity of literature comparing their views and perceptions with those of surgical faculty. Furthermore, limited data on this topic exists in developing countries. It is well established that subSaharan Africa has one of the largest surgical disease burdens, yet one of the lowest concentrations of surgical providers. $^{8}$ An in-depth assessment and comparison of learning environments in the surgical rotation between developing and developed countries may shed light on methods to improve surgical interest amongst medical students globally. The aim of this study was to evaluate and compare medical student and faculty perceptions of undergraduate surgical training and compare results between South Africa and Sweden.

\section{Materials And Methods}

\section{Background}

The University of Cape Town (UCT) Faculty of Health Sciences is the oldest medical school in sub-Saharan Africa. The UCT Bachelor of Medicine and Surgery (MBChB) programme accepts approximately 220 medical students each year. The degree comprises six years of full-time academic and clinical study. Years one to three form the foundation in which the basic sciences are taught, whereas years four to six consist predominantly of clinical teaching in the various medical and surgical disciplines. It is during the fifth year of study that medical students rotate through the various surgical disciplines, including general, orthopedic, trauma, neuro- and pediatric surgery. During the surgical rotation, UCT medical students are trained at various secondary- and tertiary-level academic hospitals.

The Karolinska Institutet (KI) is the only purely medical university in Sweden and accepts approximately 320 medical students per year. Medical school is five and a half years in duration and includes 11 semesters of study. The first four semesters focus on the basic sciences in the form of "The healthy human" and "Disease and illness" modules. The course "Clinical medicine - surgery" occupies the seventh semester and comprises the disciplines of surgery, anesthesiology, orthopedics, and oncology. Swedish medical students are trained at various hospitals, including two university and two secondary hospitals.

The surgical training at both institutions is clinically integrated throughout the undergraduate programme and offers students both clinical and theoretical instruction in the form of formal lectures, small-group tutorials, academic and clinical ward-rounds, as well as opportunities to learn in the operating theater.

\section{Study Population}

Medical student clinical exposure is varied amongst the different surgical disciplines in both South Africa and Sweden. In order to maintain homogeneity, only the general surgery rotation was evaluated. Additionally, only consultants and fellows were recruited in the faculty sample. Registrars were excluded as they themselves are in training.

Medical students from UCT and KI, who completed and passed all of the necessary examinations of their respective undergraduate general surgery rotation during the 2017 academic year, were included in this study. Similarly, employed staff in the Department or Divisions of General Surgery during the abovementioned period, both consultants and fellows, were included.

During the study period, 492 (202 to UCT and 290 to $\mathrm{KI}$ ) and 55 (20 to UCT and 35 to $\mathrm{KI}$ ) questionnaires were administered to eligible students and faculty respectively. 
Based on previous reports, a response rate of between 20 and $80 \%$ was expected.

\section{Procedure}

Ethical approval was obtained from the UCT Human Research Ethics Committee (HREC 014/2019). Following written confirmation by a representative of the KI Ethics Committee, this cross-sectional study did not require ethical approval from KI. Institutional approval was obtained after ethical approval was granted.

As there are limited reliable or validated published questionnaires regarding clinical training in surgery, a study-specific questionnaire was designed. However, the questionnaire was modelled solely from the work of De et $\mathrm{al}^{1}$ and adapted to the current study population. The questionnaire was designed through SurveyMonkey (SurveyMonkey Inc., San Mateo, CA), a secure, online survey development format. The questionnaire was administered anonymously and all participants were required to read and give informed consent prior to continuing the online survey.

The questionnaire (Supplementary Tables 1-4) consisted of demographic data including age, gender, nationality, and stage of training. Multiple choice questions, true or false questions, and five-point Likert-type questions explored the perceptions of medical students and surgical faculty regarding the current undergraduate surgical curriculum, as well as existing clinical and theoretical instructional methods.

To increase reliability, the same questionnaire was distributed to medical students and faculty except for a change in wording to correctly address the participants. The questionnaires were distributed in English for participants from UCT, and in Swedish for participants from KI.

\section{Data Management And Analysis}

After the data collection process, data were entered into Microsoft Excel 2016 (Microsoft Corp, Redmond, WA), and descriptive analysis was performed. Data were imported into SPSS 24 (Version 24.0. Armonk, NY: IBM Corp.) for inferential analysis. Likert-type data were dichotomized into two categorical groups. Pearson Chi-square or Fisher exact tests were utilized for categorical data. Student's $t$-test and the Mann-Whitney $U$-test were utilized for parametrical and non-parametrical numerical data respectively. A $p$-value of $\leq$ 0.05 was considered significant.

\section{Results}

\section{Demographics}

A total of 120 (response rate of 24.4\%) students responded, of whom 71 (59.2\%) were from KI and 67 (55.8\%) were female. The median age of the student cohort was 25.7 (range 21-40) years. No statistical difference in gender was found between students, however KI students were significantly older than UCT students $(p=0.004)$. Forty-one (response rate of $74.5 \%$ ) surgical faculty members responded, with 28 $(68.3 \%)$ based at KI. Among the total faculty cohort, 30 (73.2\%) were male, and the median age was 46.4 (range 34-64) years. KI faculty were significantly older than UCT faculty ( $p=0.009$ ). A summary of student and faculty demographic data is shown in Table 1.

\section{Perceptions Of Undergraduate Clinical And Theoretical Instruction}

As displayed in Table 2, the majority of students (53.3\%) reported receiving at least three hours of clinical teaching per week which was significantly different to the majority of faculty $(70.7 \%)$ who reported teaching less than two hours per week $(p<0.001)$. Furthermore, students believed they ought to receive significantly more teaching when compared to faculty $(p=0.018)$. Students and faculty generally agreed that students should expect to study approximately six to $20 \mathrm{hrs}$ per week outside of clinical duty.

As depicted in Figure 1, students from UCT, as well as faculty from both KI and UCT stated that "small-group tutorials" were the area of training that medical students learnt the most from $(71.4 \%$; $64.3 \%$; and $53.8 \%$; respectively). The most commonly reported area of training from KI students was "one-on-one" $(38.0 \%)$. The area that students believed to be the worst area of training was "lectures", whereas faculty reported "out-patient clinic" as the worst area of training for medical students.

Table 3 illustrates the differences in student and faculty views of the various skills absolutely necessary for a medical student to have learned by the end of his or her surgical rotation. "Proper surgical history" taking and the "ability to present patients" were skills deemed significantly more important by faculty when compared to students ( $p=0.021$ and $p=0.018$ respectively). Contrastingly, "identifying surgical complications" $(p=0.026)$, the "ability to suture" $(p=0.001)$ and "assist in theater" $(p<0.001)$, as well as knowledge of a "sterile technique" $(p=0.002)$, were skills all reported significantly more important to acquire by students when compared to faculty. 
Table I Demographic Data

\begin{tabular}{|c|c|c|c|}
\hline Medical Students $(n=\mid 20)$ & UCT $(n=49)$ & $K I(n=7 I)$ & $p$-value \\
\hline \multicolumn{4}{|l|}{ Gender - n (\%) } \\
\hline Female & $30(6 I .2)$ & $37(52.1)$ & 0.323 \\
\hline Median age - years (IQR) & $24.5(2)$ & $26.4(3)$ & $0.004^{*}$ \\
\hline Surgical faculty $(n=4 I)$ & UCT $(n=13)$ & $K I(n=28)$ & $p$-value \\
\hline \multicolumn{4}{|l|}{ Gender - n (\%) } \\
\hline Female & $6(46.2)$ & $5(17.9)$ & 0.057 \\
\hline Median age - years (IQR) & $41.6(7)$ & $48.7(11.75)$ & $0.009 *$ \\
\hline \multicolumn{4}{|l|}{ Level of training - n (\%) } \\
\hline Consultant & $10(76.9)$ & $26(92.9)$ & 0.304 \\
\hline Fellow & $3(23.1)$ & $2(7.1)$ & \\
\hline \multicolumn{4}{|l|}{ Years in surgical practice - n (\%) } \\
\hline $0-2$ & $2(15.4)$ & $0(0.0)$ & \\
\hline Female & $0(0.0)$ & $0(0.0)$ & \\
\hline $3-5$ & $2(15.4)$ & $0(0.0)$ & \\
\hline Female & I (50.0) & $0(0.0)$ & \\
\hline $6-8$ & $2(15.4)$ & $3(10.7)$ & \\
\hline Female & $2(100.0)$ & I (33.3) & \\
\hline $9-11$ & $4(30.7)$ & $6(2 I .4)$ & \\
\hline Female & $2(50.0)$ & I (I6.7) & \\
\hline$\geq 12$ & $3(23.1)$ & $19(67.9)$ & \\
\hline Female & I (33.3) & $3(15.8)$ & \\
\hline
\end{tabular}

Notes: Categorical variables analyzed with Pearson Chi-square or Fisher exact tests as appropriate. *P $\leq 0.05$ by Mann-Whitney U-test. Abbreviation: IQR, Interquartile range.

The majority of UCT students $(59.2 \%)$, KI faculty $(57.2 \%)$, and UCT faculty $(69.2 \%)$, stated that the "registrar" should be consulted first if medical students have theoretical or clinical questions about the care of patients (Figure 2). The majority of KI students (35.2\%) stated that the "intern" should be consulted first. All groups reported the "nurse" as the least likely to be consulted first.

\section{Perceptions Of Undergraduate Surgical Training}

Of the total student cohort, 51 (42.5\%) believed that faculty viewed students as an inconvenience in their dayto-day responsibilities. Furthermore, 42 (35.0\%) believed that faculty would rather not have students on the surgical team. Significant differences were found when comparing both statements with views from the total faculty cohort ( $p=0.039$ and $p=0.001$ respectively). When comparing $\mathrm{KI}$ and UCT students, a significantly higher number of UCT students believed that faculty viewed students as an inconvenience, when compared to $\mathrm{KI}$ students $(p=0.020)$.
Contrastingly, no differences were found in both statements when comparing KI and UCT faculty.

As shown in Table 4, 49 (40.8\%) students agreed that they would pursue a career in either general surgery or a surgical subspecialty. The majority of faculty $(68.3 \%)$ reported significantly more negative views on the current undergraduate surgical curriculum when compared to students $(p=0.002)$. A significant difference was also found between student groups, with the majority of UCT students $(63.3 \%)$ reporting a more negative outlook on the current surgical curriculum when compared to KI students $(p<0.001)$.

Both faculty and students believed that medical students played an important role in the surgical team. The total student cohort believed that faculty plays a significantly larger role in shaping the career of a medical student, when compared to faculty $(p<0.001)$. UCT faculty reported significantly higher consistency in the methods of evaluating students when compared to KI faculty $(p=0.009)$. However, UCT faculty reported giving 


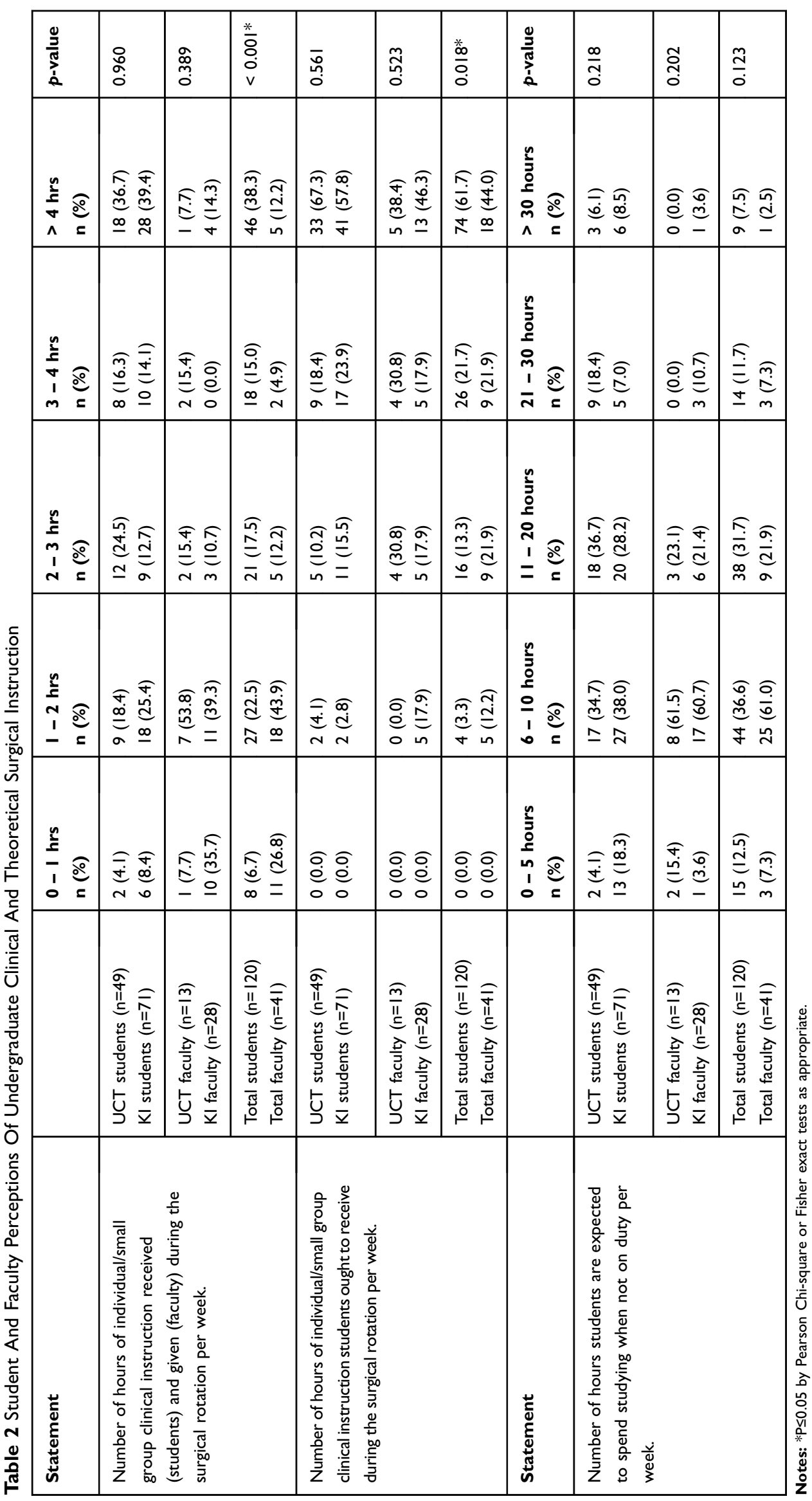




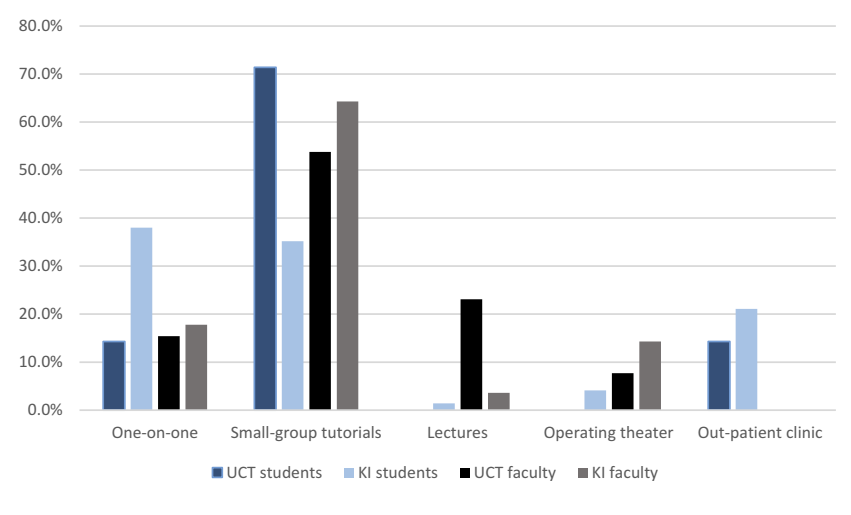

Figure I Area of training medical students learn the most from.

significantly less feedback to students during their surgical rotation when compared to KI faculty ( $p=0.043$ ).

\section{Discussion}

The current study explored perceptions of the existing surgical curriculum, not only between medical students and surgical faculty, but between students and faculty from institutions based in developing and developed countries. Students at the two institutions in the current study were similar in terms of gender, however KI students were significantly older. When compared to UCT faculty, the faculty from KI were significantly older, reported being in surgical practice longer, and were predominantly male. It has been shown that despite similar numbers of males and females graduating from medical school and completing specialist training, females still make up one of the lowest percentages of the surgical specialists. ${ }^{9}$ This is corroborated by the demographic finding in this study where, compared to UCT faculty, an inequality of gender in consultant positions exist within the KI faculty cohort, especially in those who have practiced surgery longer.

The total student cohort reported a significantly higher number of hours of clinical training received when compared to the number of hours the surgical faculty reported they actually had taught. This difference may be due to a higher proportion of the student-faculty interaction time interpreted as actual clinical training by students compared to faculty. Increased responsibility on registrars to undertake teaching of medical students, compared to consultants, may also play a role as registrars have been shown to be ideally placed to deliver teaching and clinical supervision to medical students, with studies in both developed and developing countries illustrating their benefits. ${ }^{10-12}$ Furthermore, it is postulated that surgical registrars are in fact the primary educators of medical students as both clinical and research commitments limit the teaching responsibilities of more senior faculty such as surgical consultants. ${ }^{13}$ The total student cohort also believed they ought to receive significantly more clinical instruction when compared to the surgical faculty, corroborating findings of previous studies which found that medical students desired more clinical teaching when compared to faculty perceptions. ${ }^{1,14}$

No differences were found in the expected number of hours of study outside of clinical duty when comparing both student and faculty cohorts, as well as student groups from UCT and KI. A large body of research has evaluated the changes in student perceptions and attitudes to medical education across different generations. ${ }^{15}$ The emergence of the Millennial generation, or Generation Y, has created a change in learning styles and climates, as described by Engels and de Gara. ${ }^{7}$ It has been proposed that with the arrival and ease of digital technology in the last decade, medical students have altered the way they think and process information, resulting in "difficulty in excelling in classrooms using outdated teaching methods commonly used in medical education today". ${ }^{16}$ The findings of the current study suggest however that students and faculty from both developing and developed nations may have similar perceptions and expectations of educational methods in and out of the conventional learning environment.

Except for KI students, the results of the current study support the perception that medical students learn most from small-group tutorials. KI students most commonly reported one-on-one training as the best medical student educational method. It is possible that with the ratio of medical students to faculty at medical schools in developed countries being less than that of developing countries, they may have more opportunity to teach in a oneon-one format. Conversely, students from both KI and UCT believed that lectures were the area that students learnt the least from. It has been shown in recent years that there has been a desire to move away from the commonly utilized lecture and slide presentation, and more toward small-group sessions in medical education. ${ }^{17}$ In a study where 33 didactic lectures in general surgery were reduced to eight small-group sessions, medical students in the small-group sessions obtained significantly higher examination scores. ${ }^{18}$ Furthermore, the faculty reported a positive stance on the change of teaching method, despite requiring more time to prepare for the small-group sessions. 


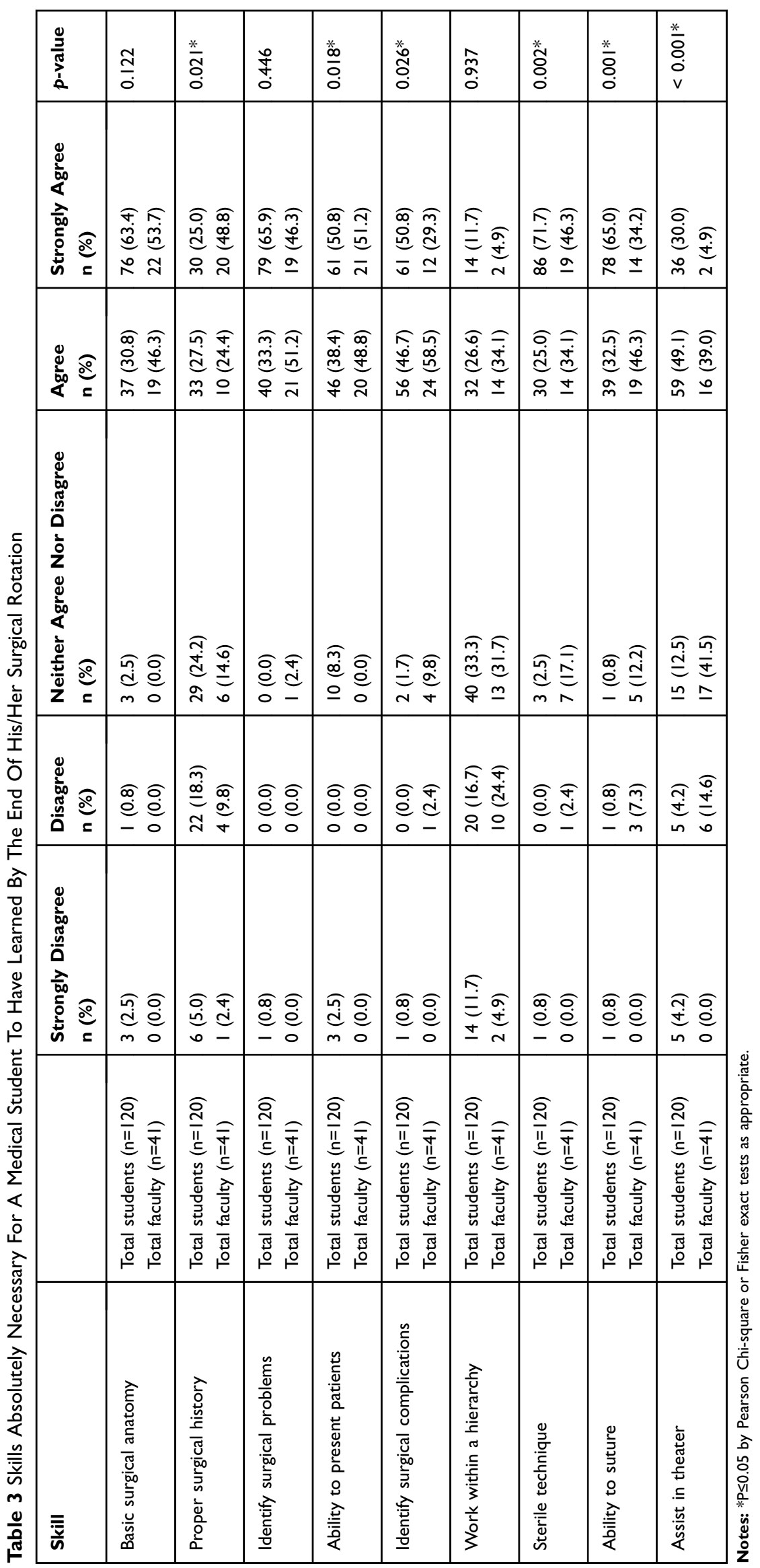




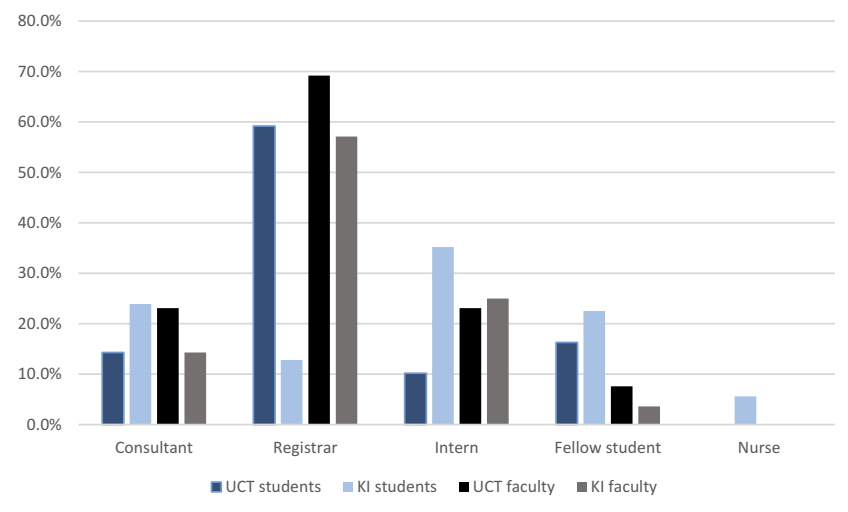

Figure 2 Whom medical students should consult first if they have theoretical or clinical questions about the care of patients.

UCT faculty believed that lectures were an area that medical students learn well from. This is not surprising as a large proportion of the UCT fifth year undergraduate general surgery rotation is lecture-based. Of concern is that despite the reported positive impact the operating theater has shown to have on the learning outcomes of medical students, ${ }^{6}$ few KI students and no UCT student reported the operating theater as an area where medical students learn well from. Whether this was due to limited exposure, or inadequate teaching while in the operating theater, is a basis for future research. What is well-established in the literature are the feelings of intimidation and dissatisfaction that students encounter while in the operating theater which has been attributed to unspecified learning objectives and students being unsure of what was expected of them. ${ }^{19,20}$ This highlights the importance of detailed instructions and clear learning outcomes for both student and educator before commencing teaching in the operating theater. Neither KI nor UCT faculty reported the out-patient clinic as an effective learning area for teaching medical students. The limited time in a busy clinic setting, as well as the often-perceived disruption to faculty workload may be some of the reasons for this finding. ${ }^{18}$ These results indicate that a change to the curriculum may be warranted. However, change may be difficult to effect due to logistical and financial constraints most medical schools are facing, especially in the developing world.

Whereas students and faculty generally agreed that certain skills need to be acquired by a medical student prior to the end of their undergraduate surgical rotation, there were significant differences in prioritizing the skills between student and faculty groups. Faculty prioritized history-taking and the ability to appropriately present patients, whereas students regarded practical skills, such as sterile technique and the ability to suture, as more important. Similar differences were reported in comparative studies which demonstrated that students tend to focus more on clinical skills during undergraduate surgical training. ${ }^{1,14}$ It has been suggested that within medical and surgical education, curricular goals have been increasingly defined by clinical competency rather than specific learning objectives. ${ }^{21}$ Previous reports have argued that at undergraduate level, the focus of surgical skills training should be for the student to properly identify surgical patients and therefore know when to refer for surgical intervention. ${ }^{14}$ As each skill explored in the current study is important in its own right, reconciliation of difference in perspectives is likely to improve skills development. Faculty is therefore tasked to establish clear goals and motivation for the need to acquire certain skills, thereby creating explicit expectations for medical students during their undergraduate surgical training.

The majority of respondents believed that medical students should first consult with registrars if any questions arise regarding the care of patients, which is in keeping with previous literature reports. ${ }^{1}$ Interestingly, KI students reported the intern as the preferred first contact. Whether KI students have more day-to-day interaction with interns compared to registrars, thus perceiving them as their favored initial contact, is questionable and may be explored in future studies. It has been shown that South African registrars spend up to $40 \%$ of their day teaching undergraduate medical students. ${ }^{22}$ Despite this large proportion of time spent in educating students, registrars have limited, if any, formal teaching in education. ${ }^{23}$ Therefore, many institutions have developed a Registrar- (or Resident)-as-Teacher programme aiming to improve their teaching skills. Recent results of such programmes have confirmed its positive impact. ${ }^{10}$ It stands to reason that as medical students spend a significant amount of time with registrars, it should be logical for academic institutions to invest in improving their teaching skills, and to provide them with formal teacher training.

One of the most disconcerting findings in the current study was student perceptions that they were an inconvenience to clinical responsibilities, and the belief that faculty would rather not have students on the surgical team. These views amongst medical students have been reported previously. ${ }^{1,9,24}$ Often accompanied by feelings of helplessness, these perceptions may create adversity to surgery as a discipline during the undergraduate surgical rotation. Despite this negative perception by students, both 


\begin{tabular}{|c|c|c|c|c|c|c|c|c|c|c|c|c|c|c|c|}
\hline 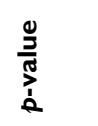 & \multicolumn{2}{|l|}{ 吕 } & $\begin{array}{l}* \\
\\
0 \\
\mathrm{v} \\
\mathrm{v}\end{array}$ & $\frac{m}{0}$ & $\begin{array}{l}\stackrel{*}{\tilde{\delta}} \\
0 \\
0\end{array}$ & 吕 & $\begin{array}{l}\frac{\sigma}{\alpha} \\
0 \\
0\end{array}$ & $\begin{array}{l}\bar{\sigma} \\
\text { ót }\end{array}$ & $\begin{array}{l}\text { 资 } \\
0\end{array}$ & 志 & $\begin{array}{l}* \\
\frac{*}{0} \\
0 \\
v\end{array}$ & \multicolumn{2}{|l|}{ 卷 } & \multicolumn{2}{|l|}{$\begin{array}{l}\text { *. } \\
\text { co } \\
0\end{array}$} \\
\hline 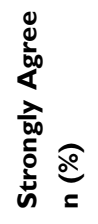 & 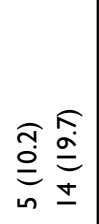 & 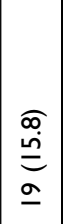 & 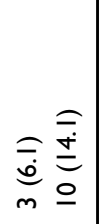 & 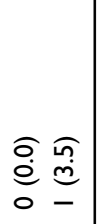 & 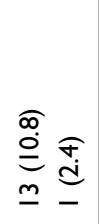 & $\begin{array}{ll}\underset{\sigma}{\infty} & \widehat{T} \\
\stackrel{\infty}{=} & \underset{ \pm}{ \pm} \\
\sigma & m\end{array}$ & 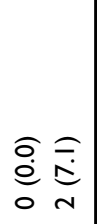 & 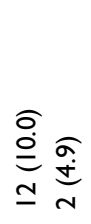 & 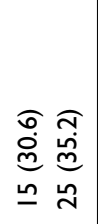 & $\begin{array}{l}\hat{0} \\
\stackrel{0}{0} \\
-\end{array}$ & 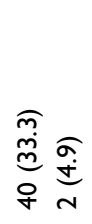 & 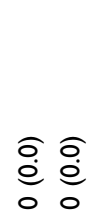 & $\begin{array}{l}\hat{0} \\
\stackrel{0}{0}\end{array}$ & $\begin{array}{ll}0 & 0 \\
0 & 0 \\
0 & 0 \\
0 & 0\end{array}$ & $\frac{a}{\stackrel{0}{0}}$ \\
\hline 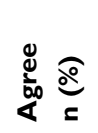 & 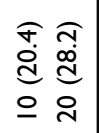 & 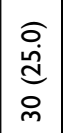 & 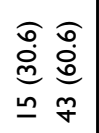 & 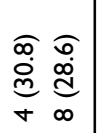 & 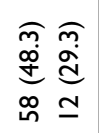 & 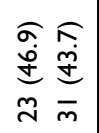 & 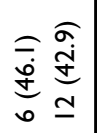 & 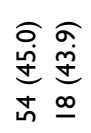 & 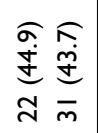 & 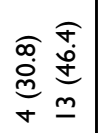 & 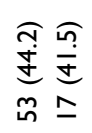 & 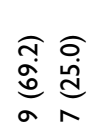 & $\begin{array}{l}\underline{0} \\
\dot{0} \\
\underline{0} \\
\underline{0}\end{array}$ & 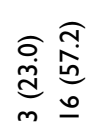 & $\begin{array}{l}\widehat{f} \\
\dot{d} \\
a \\
a\end{array}$ \\
\hline 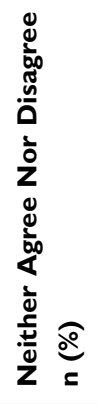 & $\begin{array}{l}\text { ñ } \\
\stackrel{\sqrt{n}}{\mathbb{d}} \\
=\underline{\Xi} \\
=\underline{0}\end{array}$ & 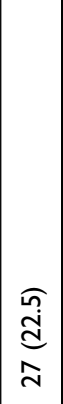 & 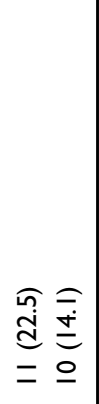 & 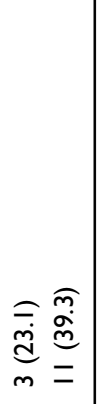 & 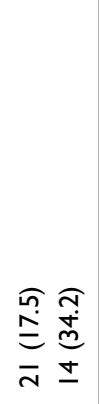 & 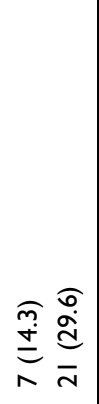 & 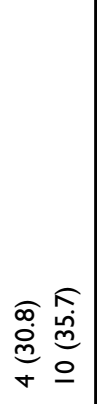 & 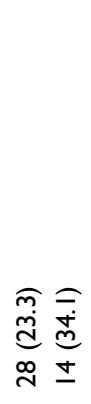 & 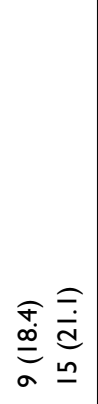 & 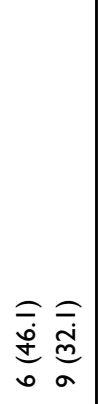 & 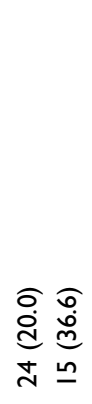 & 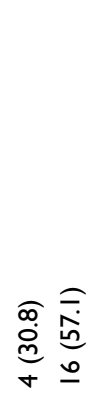 & 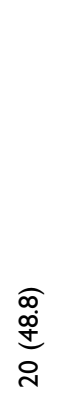 & 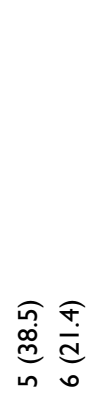 & $\begin{array}{l}\widehat{o} \\
\stackrel{d}{d} \\
= \\
=\end{array}$ \\
\hline 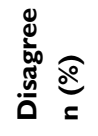 & 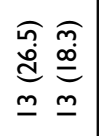 & $\begin{array}{l}\frac{r}{i} \\
\stackrel{i}{c} \\
\stackrel{d}{d}\end{array}$ & 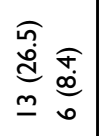 & 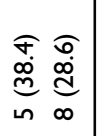 & 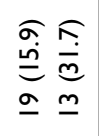 & 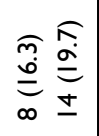 & 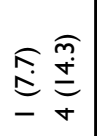 & 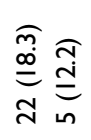 & $\begin{array}{ll}\overline{\bar{\theta}} & \widehat{o} \\
\mathrm{~m} & 0 \\
\end{array}$ & 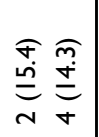 & 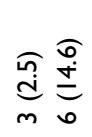 & 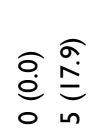 & 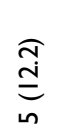 & 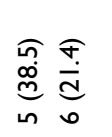 & $\begin{array}{l}\text { ô } \\
\stackrel{d}{d} \\
=\end{array}$ \\
\hline 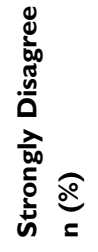 & 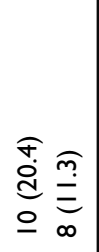 & 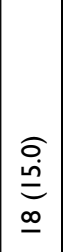 & $\begin{array}{l}\underset{j}{\stackrel{\infty}{=}} \underset{\sim}{\stackrel{\infty}{d}} \\
\sim\end{array}$ & 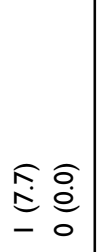 & 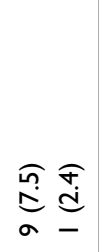 & 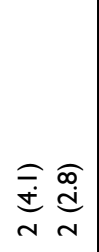 & 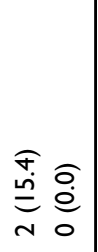 & 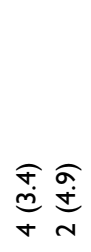 & $\begin{array}{l}\widehat{\partial} \\
\stackrel{0}{0} \\
0\end{array}$ & $\begin{array}{l}\widehat{\sigma} \\
\stackrel{0}{0} \\
0\end{array}$ & 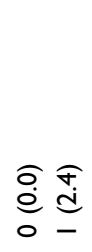 & $\begin{array}{ll}\widehat{O} & \widehat{O} \\
\stackrel{e}{e} & 0 \\
0 & 0\end{array}$ & $\begin{array}{l}\hat{0} \\
\stackrel{0}{0}\end{array}$ & $\begin{array}{l}\widehat{\partial} \\
\stackrel{0}{\dot{e}} \\
0\end{array}$ & 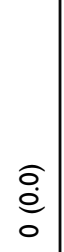 \\
\hline & 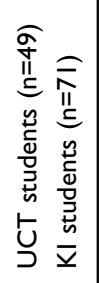 & 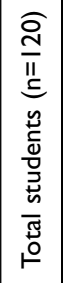 & 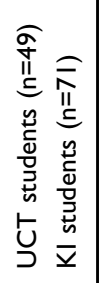 & 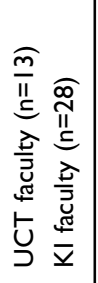 & 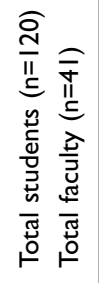 & 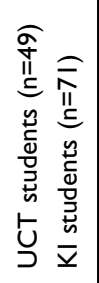 & 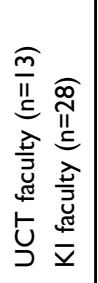 & 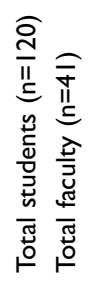 & 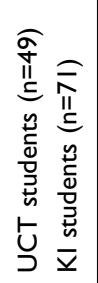 & 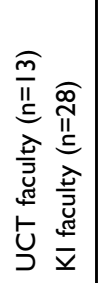 & 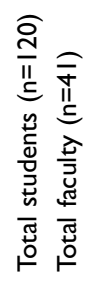 & 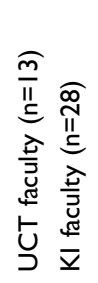 & 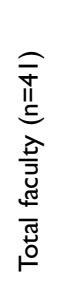 & 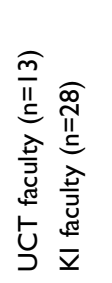 & 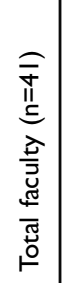 \\
\hline 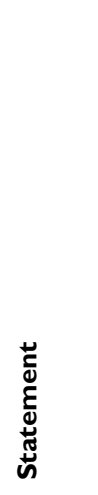 & 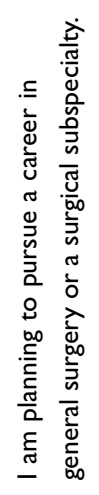 & & 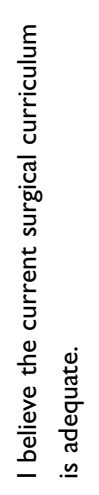 & & & 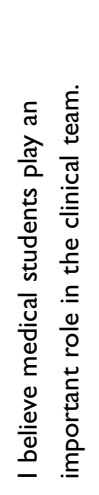 & & & 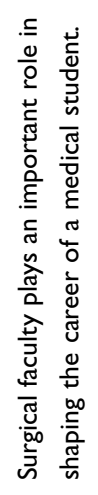 & & & 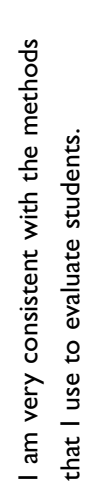 & & 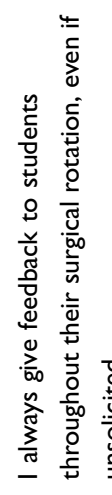 & \\
\hline
\end{tabular}


faculty and student cohorts agreed that medical students play an important role in the surgical team. However, the exact role needs to be defined more specifically. It has been suggested that medical students may not be critical in day-to-day care of surgical patients, but that focus should be on learning the pathophysiology of the surgical patient, and how to be a contributing member of the surgical team. ${ }^{25}$ To more effectively accommodate students in the clinical setting, it has been proposed that specific ward-related tasks be created for students to complete, and to more clearly outline student roles during the surgical rotation. ${ }^{14}$ It has also been suggested that specific clinical education wards be created, where most clinical tasks, when appropriate, may be performed by students under faculty guidance. ${ }^{26}$

One of the most important results from the current study is the negative outlook UCT students and faculty had on the adequacy of the current surgical curriculum when compared to perceptions from KI. Additionally, the combined faculty cohort from both institutions viewed the curriculum in a more negative light when compared to the combined student cohort. A study from the United Kingdom $^{27}$ reported a generally low level of satisfaction regarding surgical sciences teaching, with less than half of medical students stating they were prepared for emergency general surgery when they graduated as junior doctors. Evidence has shown that both students and tutors perceive the medical curriculum as misaligned, and that misalignment causes resentment amongst medical students. ${ }^{28}$ Surgical training is an essential aspect of the undergraduate curriculum and therefore medical schools and surgical educators are challenged to create effective partnerships with the aim of delivering effective surgical teaching for medical students.

Another factor that has been shown to influence medical student perceptions of surgery is faculty evaluation and feedback. Seen as an essential skill required for learner improvement, effective feedback may support the learner in accomplishing defined goals. ${ }^{29}$ In one of a few studies evaluating perceptions of undergraduate surgical training amongst medical students in the developing world, a study from Nigeria ${ }^{30}$ reported that just over half of students believed that feedback on their performance was adequate. The current study found UCT faculty to be significantly more consistent in evaluating students when compared to KI faculty. However, UCT faculty were significantly less likely to give feedback to students. This result, which may contribute to the negative perceptions of medical students about their surgical rotation, is in keeping with previous literature which found that faculty were indifferent about their feedback to students. ${ }^{1}$ Constructive feedback is an important aspect of the responsibilities of an educator. It has been suggested that increased accountability for inadequate quality of teaching would resolve many issues that students and faculty may experience. ${ }^{18}$

Similar to findings from previous studies, ${ }^{1,31}$ the current study demonstrated general agreement amongst all respondents that surgical faculty play an important role in shaping the career of a medical student. However, students from both UCT and KI reported significantly higher agreement compared to faculty. In a survey of medical students and surgical faculty, Quillin et $\mathrm{al}^{31}$ reported that surgical faculty failed to recognize their influence on medical students. Once more, this perception may influence medical student views of surgery, and ultimately have implications for a potential surgical career.

A number of methodological limitations in the current study have been identified. The descriptive, cross-sectional study design inherently compromises validity. The overall response rate of medical students was low compared to that of surgical faculty, which may also limit the validity of results. There is no consensus on what constitutes an adequate response rate, as it has been shown that it depends on the way in which data is used..$^{32}$ For example, Nulty $^{33}$ describes that even one response that provides information in a teaching evaluation survey has served its purpose in bringing about potential improvements. Although based on previous research, the questionnaire used in this study was not validated. However, to date no validated questionnaire exists for evaluating the efficacy of surgical training and mentorship in medical students, which causes an inherent limitation. Despite conducting this study at two institutions which include several teaching hospitals, only one academic year was evaluated, which may have introduced population bias. As registrars were not included in this study, results may have been confounded as students may have found it problematic in reporting on teaching solely done by consultants and fellows.

\section{Conclusion}

Significant differences exist in the perceptions of medical students and surgical faculty regarding undergraduate surgical training in both South Africa and Sweden. These differences may have negative implications for the 
fostering of surgical interest amongst medical students, as well as the potential for students to pursue a career in surgery. The differences observed in students and surgical faculty in developing and developed countries illustrate potential dissimilarities in teaching and learning styles, areas of focused teaching, and overall roles and expectations of medical students within the current undergraduate surgical curricula.

Most surgical faculty members aspire to be effective teachers and aim to ensure that the medical students they teach become knowledgeable and competent medical practitioners. However, a number of factors may frustrate their efforts such as weaknesses in the institutional curriculum, cultural differences, and environmental changes. By focusing on aspects that may dispel the negative and misaligned perceptions of surgical training between medical students and surgical faculty, along with valuing the student-centered and problem-orientated approaches to learning, medical students may be equipped with crucial surgical skills and knowledge, as well as a reaffirmed interest in surgery.

\section{Acknowledgments}

This study was in fulfilment of the UCT Master of Philosophy (Surgery) degree for Dr Alex J. Scott.

\section{Disclosure}

The authors report no conflicts of interest in this work.

\section{References}

1. De SK, Henke PK, Ailawadi G, Dimick JB, Colletti LM. Attending, house officer, and medical student perceptions about teaching in the third-year medical school general surgery clerkship. J Am Coll Surg. 2004;199:932-942. doi:10.1016/j.jamcollsurg.2004.08.025

2. Yilmaz ND, Velipasaoglu S, Ozan S, et al. A multicenter study: how do medical students perceive clinical learning climate? Med Educ Online. 2016;21:30846. doi:10.3402/meo.v21.30846

3. Cohen J. Social, emotional, ethical and academic education: creating a climate for learning, participation in democracy and well-being. Harv Educ Rev. 2006;76:201-237. doi:10.17763/haer.76.2.j44854x15 24644vn

4. Epstein RM. Assessment in medical education. $N$ Engl $J$ Med. 2007;356:387-396. doi:10.1056/NEJMra054784

5. Aggarwal R, Hance J, Darzi A. Surgical education and training in the new millennium. Surg Endosc. 2004;18:1409-1410. doi:10.1007/ s00464-004-8238-x

6. O'Neill R, Shapiro M, Merchant A. The role of the operating room in medical student education: differing perspectives of learners and educators. J Surg Educ. 2018;75(1):14-28. doi:10.1016/j.jsurg.201 7.06 .013

7. Engels PT, de Gara C. Learning styles of medical students, general surgery residents, and general surgeons: implications for surgical education. BMC Med Educ. 2010;10(51):1-6. doi:10.1186/14726920-10-51
8. Riviello R, Ozgediz D, Hsia RY, Azzie G, Newton M, Tarpley J. Role of collaborative academic partnerships in surgical training, education, and provision. World J Surg. 2010;34:459-465. doi:10.1007/s00268009-0360-4

9. Bruce AN, Battista A, Plankey MW, Johnson LB, Marshall MB. Perceptions of gender-based discrimination during surgical training and practice. Med Educ Online. 2015;20(1):25923. doi:10.3402/meo. v20.25923

10. Hill AG, Yu T, Barrow M, Hattie J. A systematic review of residentas-teacher programmes. Med Educ. 2009;43:1129-1140. doi:10.1111/ j.1365-2923.2009.03523.x

11. Thampy H, Agius S, Allery LA. The motivation to teach as a registrar in general practice. Educ Prim Care. 2013;24:244-250.

12. Makama JG, Ameh EA. Quality of teaching provided by surgical residents: an evaluation of the perception of medical students. Niger $J$ Med. 2011;20(3):341-344.

13. Nguyen SQ, Divino CM. Surgical residents as medical student mentors. Am J Surg. 2007;193:90-93. doi:10.1016/j.amjsurg.2006.07.011

14. Quillin RC, Pritts TA, Tevar AD, Hanseman DJ, Edwards MJ, Davis BR. Students' expectations on the surgery clerkship exceed those of residents and faculty. J Surg Res. 2013;184:495-500. doi:10.1016/j. jss.2013.04.048

15. Evans $\mathrm{CH}$, Schenarts KD. Evolving educational techniques in surgical training. Surg Clin. 2016;96:71-88. doi:10.1016/j.suc.201 5.09 .005

16. Prensky M. Digital natives, digital immigrants. Horizon. 2001;9:1-6.

17. Jaarsma AD, de Grave WS, Muijtjens AM, Scherpbier AJ, van Beukelen P. Perceptions of learning as a function of seminar group factors. Med Educ. 2008;42:1178-1184. doi:10.1111/j.13652923.2008.03170.x

18. DaRosa DA, Skeff K, Friedland JA, et al. Barriers to effective teaching. Acad Med. 2011;86(4):453-459. doi:10.1097/ACM.0b0 13e31820defbe

19. Chapman SJ, Hakeem AR, Marangoni G, Prasad KR. How can we enhance undergraduate medical training in the operating room? A survey of student attitudes and opinions. J Surg Educ. 2013;70 (3):326-333. doi:10.1016/j.jsurg.2013.01.008

20. Ravindra P, Fitzgerald JE, Bhangu A, Maxwell-Armstrong CA. Quantifying factors influencing operating theater teaching, participation, and learning opportunities for medical students in surgery. $J$ Surg Educ. 2013;70(4):495-501. doi:10.1016/j.jsurg.2013.02.011

21. Daelmans HE, Hoogenboom RJ, Donker AJ, Scherpbier AJ, Stehouwer CD, van der Vleuten CP. Effectiveness of clinical rotations as a learning environment for achieving competences. Med Teach. 2004;26:305-312. doi:10.1080/01421590410001683195

22. Smit EJ. Evaluation of a pilot 'registrar-as-a-teacher' faculty development program at Stellenbosch University [dissertation]. Accra: Stellenbosch University; 2014.

23. Morrison EH, Hollingshead J, Hubbell FA, Hitchcock MA, Rucker L, Prislin MD. Reach out and teach someone: generalist residents' needs for teaching skills development. Fam Med. 2002;34:445-450.

24. Marshall DC, Salciccioli JD, Walton SJ, Pitkin J, Shalhoub J, Malietzis G. Medical student experience in surgery influences their career choices: a systematic review of the literature. J Surg Educ. 2015;72(3):438-445. doi:10.1016/j.jsurg.2014.10.018

25. Lewis BD, Leisten A, Arteaga D, Treat R, Brasel K, Redlich PN. Does the surgical clerkship meet the needs of practicing primary care physicians? Wis Med J. 2009;108(8):398.

26. Lindblom P, Scheja M, Torell E, Astrand P, Felländer-Tsai L. Learning orthopaedics: assessing medical students' experiences of interprofessional training in an orthopaedic clinical education ward. $J$ Interprof Care. 2007;21(4):413-423. doi:10.1080/135618207014 01346

27. Lee MJ, Drake TM, Malik TA, et al. Has the bachelor of surgery left medical school? - a national undergraduate assessment. J Surg Educ. 2016;73(4):655-659. doi:10.1016/j.jsurg.2016.01.005 
28. Agha RA, Papanikitas A, Baum M, Benjamin IS. The teaching of surgery in the undergraduate curriculum. Part II - importance and recommendations for change. Int $J$ Surg. 2005;3(1):151-157. doi:10.1016/j.ijsu.2005.03.016

29. Bing-You RG, Trowbridge RL. Why medical educators may be failing at feedback. JAMA. 2009;302(12):1330-1331. doi:10.1001/jama.2009.1393

30. Ekenze SO, Ugwumba FO, Obi UM, Ekenze OS. Undergraduate surgery clerkship and the choice of surgery as a career: perspective from a developing country. World J Surg. 2013;37(9):2094-2100. doi:10.1007/s00268-013-2073-y
31. Quillin RC, Pritts TA, Davis BR, et al. Surgeons underestimate their influence on medical students entering surgery. J Surg Res. 2012;177:201-206. doi:10.1016/j.jss.2012.05.064

32. Fan W, Yan Z. Factors affecting response rates of the web survey: a systematic review. Comput Human Behav. 2010;26(2):132-139. doi:10.1016/j.chb.2009.10.015

33. Nulty DD. The adequacy of response rates to online and paper surveys: what can be done? Assess Eval High Educ. 2008;33 (3):301-314. doi:10.1080/02602930701293231

\section{Publish your work in this journal}

Advances in Medical Education and Practice is an international, peerreviewed, open access journal that aims to present and publish research on Medical Education covering medical, dental, nursing and allied health care professional education. The journal covers undergraduate education, postgraduate training and continuing medical education including emerging trends and innovative models linking education, research, and health care services. The manuscript management system is completely online and includes a very quick and fair peer-review system. Visit http://www.dovepress.com/testimonials.php to read real quotes from published authors. 